\title{
PercepÇão da Gestante sobre o CONSUMo de drogas ilí́citas na GESTAÇÃO
}

\author{
Graciela Lima Costa Portela \\ Lívia Moreira Barros ${ }^{2}$ \\ Natasha Marques Frota ${ }^{2}$ \\ Anna Paula Pequeno Landim ${ }^{3}$ \\ Joselany Áfio Caetano ${ }^{4}$ \\ Francisca Lucélia Ribeiro de Farias ${ }^{5}$
}

Objetivou-se identificar as repercussões do uso de drogas na gravidez e as consequências para o recém-nascido. Trata-se de estudo qualitativo, realizado em uma maternidade pública de Fortaleza, Ceará. Os sujeitos da pesquisa foram nove puérperas. Foram realizadas entrevistas semiestruturadas. As principais drogas utilizadas foram maconha, cocaína e crack. Identificaram-se danos prejudiciais em todos os recém-nascidos, entres os quais destacam-se: sífilis congênita, icterícia, baixo peso ao nascer, prematuridade, desconforto respiratório e infecção neonatal. Apesar de o uso de drogas ser assunto considerado como tema transversal, a discussão e a troca de experiências entre os profissionais são pouco frequentes, dificultando a identificação dos fatores de risco e das implicações ocasionadas na saúde da mulher e da criança, devido ao uso de drogas durante a gestação.

Descritores: Usuários de Drogas; Gravidez; Recém-Nascido.

\footnotetext{
${ }^{1}$ Enfermeira.

2 Mestranda, Universidade Federal do Ceará, Fortaleza, CE, Brasil.

${ }^{3}$ Aluna do curso de graduação em Enfermagem, Universidade de Fortaleza, Fortaleza, CE, Brasil.

${ }^{4}$ PhD, Professor Adjunto, Universidade Federal do Ceará, Fortaleza, CE, Brasil.

${ }^{5} \mathrm{PhD}$, Professor Titular, Universidade de Fortaleza, Fortaleza, CE, Brasil.
} 


\section{Perception of PRegnant on CONSUMPtion OF ILliCit DRUGS IN PREgnancy}

This study aimed to identify the effects of drug use in pregnancy and its consequences for the newborn. Qualitative study accomplished in a public maternity in Fortaleza. The subjects of the research were nine postpartum. Semi-structured interviews were performed. The main drugs used were marijuana, cocaine and crack. It was identified damage in all newborns, among which stand out: congenital syphilis, jaundice, low birth weight, prematurity, respiratory distress and neonatal infection. Despite the use of drugs is a matter considered a transversal theme, discussion and exchange of experiences among professionals are rare, hindering the identification of risk factors and the implications arising in health of women and child due to drug use during gestation.

Descriptors: Drug Users; Pregnancy; Infant, Newborn.

\section{Percepción de la embarazada sobre el CONSUMo de drogas ilícitas en LA GESTACIÓN}

Se objetivó identificar las repercusiones del uso de drogas en el embarazo y las consecuencias para el recién nacido. Estudio cualitativo, realizado en una maternidad pública de Fortaleza. Los sujetos de la investigación fueron nueve puérperas. Fueron realizadas entrevistas semi-estructuradas. Las principales drogas utilizadas fueron marihuana, cocaína y crack. Se identificó daños prejudiciales en todos los recién nacidos, entres quiénes se destaca: sífilis congénita, ictericia, bajo peso al nacer, precocidad, desaliento respiratorio e infección neonatal. A pesar del uso de drogas ser un asunto considerado un tema transversal, la discusión y el cambio de experiencias entre los profesionales son poco frecuente, dificultando la identificación de los factores de riesgo y de las implicaciones ocasionadas en la salud de la mujer y del niño debido al uso de drogas durante la gestación.

Descriptores: Consumidores de Drogas; Embarazo; Recién Nacido.

\section{Introdução}

Estudos evidenciam aumento no uso de drogas, como maconha, ansiolíticos, anfetamínicos, cocaína e crack. Segundo os dados publicados no Relatório Mundial de Drogas, de 2007, da Organizacão das Nacões Unidas (ONU), no Brasil, houve aumento do uso de cocaína de 0,4\% (em 2001) para 0,7\% (em 2005), sendo considerado um dado importante, assim como o aumento do uso da maconha. A maconha foi a droga ilícita que apresentou o maior incremento de uso nos últimos anos, tendo sua porcentagem de uso aumentada de 1\%, em 2001, para $2,6 \%$, em 2005. A ONU considera que esse aumento é um reflexo da facilidade de obtenção da droga no país ${ }^{(1-4)}$.
Assim, o uso de drogas ilícitas constitui importante problema de saúde pública na sociedade e, quando o grupo de risco é de gestantes, esse problema ganha repercussão maior, pois a exposição dessas mulheres às substâncias psicoativas pode levar ao comprometimento irreversível da integridade do binômio mãe/feto ${ }^{(5)}$.

Uma pesquisa nacional sobre uso de drogas nos EUA fornece tendência ao consumo de álcool, tabaco e drogas ilícitas durante a gestação. Em 1998, o uso de drogas ilícitas foi de 3,1\%, em 1999, 4\%, em 2000-2001, 3,7\%, em 2002-2003, 4,3\%, no período de 2004 a 2005, com $3,9 \%$ em 2006-2007, nas gestantes ${ }^{(6-7)}$. 
Dentre as complicações que o feto pode apresentar devido à exposição ao uso de drogas pela mãe, durante a gestação, tem-se: prematuridade, baixo peso ao nascer, diminuição do perímetro cefálico, deslocamento de placenta, acarretando, em alguns casos, o aborto $^{(8)}$.

Substâncias como anfetaminas, cocaína e nicotina podem ser transferidas, juntamente com os transportadores de nutrientes, favorecendo a competição favorável, o que reduz a distribuição de nutrientes para o feto, e contribui para o déficit de crescimento $^{(8)}$.

O rastreamento durante a consulta pré-natal é a melhor estratégia para identificar as usuárias de droga e, também, os fatores de risco para o consumo pelas gestantes, a exemplo: baixa autoestima, problemas financeiros, ansiedade e problemas nos relacionamentos afetivos, em especial com o parceiro $^{(8)}$.

Assim, a detecção precoce dos fatores de risco relacionados ao uso de drogas pelas gestantes, aliada à participação de profissionais qualificados, permitirá o direcionamento correto das medidas necessárias para melhorar a qualidade da gestação tanto para a mãe como para o feto, o que pode contribuir para a diminuição das complicações obstétricas $^{(9)}$.

Diante da análise situacional dos riscos prejudiciais ao binômio mãe/filho, surge a questão: quais repercussões que o uso de drogas ilícitas durante a gestação causa para a gestante e para o seu filho? Sendo assim o objetivo desta investigação foi identificar as repercussões do uso de drogas na gravidez e as consequências para o recémnascido.

Uma compreensão do uso de drogas ilícitas na gestação é importante para abordar esse problema de forma eficaz, uma vez que pode contribuir para uma reflexão crítica entre os enfermeiros que atuam diretamente com essas gestantes, com ações de promoção da saúde que muitas vezes são negligenciadas.

\section{Métodos}

Trata-se de estudo descritivo de natureza qualitativa, realizado em uma maternidade pública de um hospitalescola situada em Fortaleza, Ceará, Brasil.

A coleta de dados ocorreu no período de abril a maio de 2010, e o processo investigativo fez-se por meio de entrevista semiestruturada com nove puérperas. Cada participante foi convidada por meio de abordagem verbal, preservando a identidade, sendo que o nome da participante foi substituído por nome de flor.

Para a seleção das participantes na pesquisa, foram utilizados os seguintes critérios: puérperas usuárias de drogas internadas na referida instituição e aquelas cujos filhos apresentaram alguma complicação devido ao uso de drogas na gestação, sendo excluídas aquelas que não apresentavam condições física e emocional.

O número de sujeitos foi condicionado ao critério de saturação dos dados, que ocorre quando as informações tornam-se repetidas ou o acréscimo de novos dados for mínimo para serem submetidos aos procedimentos de análise $^{(10)}$.
$\mathrm{O}$ instrumento da entrevista continha dados sociodemográficos, abuso de drogas na gestação, adesão ao pré-natal, sentimento da puérpera quanto ao recém-nascido, conhecimento quanto ao uso de drogas na gestação e situação saúde/doença, bem como busca ativa nos prontuários da puérpera e do recém-nascido.

Para análise das informações emergidas das entrevistas, utilizou-se a análise de conteúdo, na modalidade temática, definida como uma técnica que consiste em apurar descrições de conteúdo aproximativas, subjetivas, para pôr em evidência a objetividade, a natureza e as forças relativas aos estímulos, às quais o sujeito é submetido ${ }^{(11)}$.

Para que essa análise ocorra de modo sistemático, são propostas três fases distintas. A primeira, chamada préanálise, tem por objetivo a organização das ideias iniciais, levando à "elaboração de indicadores que fundamentem a interpretação final"; na segunda fase, exploração do material, é realizada a decomposição do material coletado e agrupamento em unidades de significado, utilizando codificação específica; na terceira fase, chamada tratamento dos resultados, deve haver a descrição e posterior interpretação das categorias evidenciadas ${ }^{(11)}$.

Assim, na primeira fase, realizou-se a leitura flutuante com a finalidade de permitir que se estabelecesse contato com as respostas dos sujeitos e conhecesse o texto, para que então pudessem ser verificadas as primeiras impressões, as quais se consolidariam somente na última etapa.

$\mathrm{Na}$ fase de organização e exploração do material fezse a codificação das entrevistas, identificando as puérperas por nomes de flores. Nesse momento, após várias leituras, retiraram-se do texto palavras, frases ou parágrafos que apresentassem coerência com os objetivos do estudo e possibilitassem delinear as primeiras ideias agrupadas.

$\mathrm{Na}$ última fase, o reagrupamento das unidades de significado, após várias leituras e releituras, permitiu evidenciar as categorias finais: baixa adesão ao pré-natal, atitude da puérpera quanto à maternidade, lacunas no conhecimento das puérperas quanto ao efeito do uso de drogas na gestação e situação de saúde/doença das puérperas.

Este estudo foi realizado perante assinatura espontânea do Termo de Consentimento Livre e Esclarecido (TCLE) pelas puérperas, respeitando os princípios da Resolução $196 / 96$, no que se refere a pesquisas com seres humanos ${ }^{(12)}$, após ser aprovado pelo Comitê de Ética em Pesquisa da Maternidade, sob Protocolo n ${ }^{\circ} 021 / 10$.

\section{Resultados}

Foram entrevistadas nove puérperas. A faixa etária foi entre 15 e 28 anos, sendo a média de idade de 20,6 anos. Seis das entrevistadas eram primíparas e três multíparas. Em relação ao grau de escolaridade, apenas duas possuíam o ensino fundamental completo, sendo que sete não haviam completado o ensino fundamental. Quanto à atividade laboral uma era costureira, uma ex-profissional do sexo, uma era moradora de rua e as outras seis participantes não exerciam atividade laboral.

As principais consequências do uso de drogas para o recém-nascido $(\mathrm{RN})$ foram: icterícia, prematuridade, 
infecção neonatal, baixo peso ao nascer, desconforto respiratório e sífilis congênita.

Seis das participantes realizaram a sorologia para sífilis e duas tiveram a informação ignorada. Todas as puérperas que realizaram o VDRL tiveram o resultado positivo e quatro transmitiram a sífilis para o seu concepto.

Os fatores de risco relacionados ao uso de drogas na gestação mais citados pelas entrevistadas foram os seguintes: problemas familiares, ausência de parceiro, instabilidade financeira, baixa autoestima e solidão.

Mediante a descrição e documentação das falas das puérperas foram identificadas as categorias mostradas a seguir.

\section{Baixa adesão ao pré-natal}

O objetivo do pré-natal é investigar o estado de saúde materna e do feto, a fim de evitar desfechos desfavoráveis, entretanto, para que isso ocorra é importante que o prénatal seja de início precoce e assíduo, porém, os resultados do estudo apontaram que sete puérperas não realizaram o pré-natal e as que fizeram evidenciaram baixo número de consultas. Como profissionais de saúde deve-se atentar para problemas como esses e sobre a necessidade de maior divulgação dos objetivos e finalidades do programa; e a enfermagem tem papel importante dentro do programa de pré-natal, no sentido de apontar a necessidade de rastrear usuárias de drogas ilícitas no início da gestação.

Não fui porque tava me drogando no meio do mundo (Lírio).

... queria só saber se tava grávida mesmo! (Rosa). (Margarida).

... dizia para minha mãe que ia para o pré-natal e ia usar

É muito ruim. Deixei de fazer o pré-natal pra ficar me drogando. Deixei de cuidar dela... da saúde dela. Prejudicou bastante (Jasmim).

Rosa e Margarida compareceram apenas a uma consulta na unidade de atenção básica, e ao serem questionadas pelo motivo que as levou a iniciar o acompanhamento do prénatal responderam que somente queriam saber se estavam grávidas e motivo para ausentar-se de casa e usar droga. Elas reconhecem o prejuízo para a saúde do recém-nascido, entretanto, não dão importância ao fato.

Essa situação é preocupante, pois mesmo sabendo dos riscos à saúde, devido ao uso de drogas ilícitas, as puérperas continuaram fazendo uso e deixando de lado o acompanhamento pré-natal. Frente a essa realidade, torna-se pertinente a conscientização dessas mulheres e o planejamento de procedimentos e ações adequadas para identificar os grupos de risco e propor intervenções efetivas com vistas a prevenir esses problemas.

\section{Atitude da puérpera quanto à maternidade}

As relações familiares são prejudicadas devido ao abuso de drogas. Isso pode ser percebido nas falas das puérperas Violeta e Girassol, as quais estavam vivenciando a quinta e a terceira gestação, respectivamente, e doaram seus filhos por não serem capazes de assumir o papel de mãe. (Violeta).

... eu dei meus filhos! Não me lembro onde deixei eles...

... eu dei meus filhos! Não me arrependo de ter dado! (Girassol).
Comecei a usar na gestação. Sou doida. Tava com problemas com meu marido e acabei achando que aquilo era a solução (Rosa).

O período gravídico-puerperal é a fase de maior incidência de transtornos psíquicos na mulher, necessitando essas de atenção especial para manter ou recuperar o bem-estar, e para prevenir dificuldades para os cuidados com o filho ${ }^{(13)}$.

A ausência de boa estrutura familiar e relação instável com o parceiro leva a gestante a uma situação de desespero ao ponto de elas doarem seus filhos. Essa instabilidade associada ao uso de drogas mostra cada vez mais o quanto essas mulheres encontram-se susceptíveis e despreparadas para assumir a responsabilidade da maternidade.

Por isso, além do pré-natal, o planejamento familiar deve merecer atenção especial nas unidades de saúde, uma vez que o seu controle repercutirá na possível diminuição dos casos de gestação, em especial a gestação precoce.

Lacunas no conhecimento das puérperas quanto ao efeito do uso de drogas na gestação

Além do despreparo quanto à gestação precoce, tem-se, ainda, a falta de conhecimento dessas sobre o uso de drogas e seus efeitos durante a gestação e as consequências para o recém-nascido, como foi evidenciado nas falas abaixo.

... pensava que não tinha nada ver, que não ia fazer mal ao bebê (Orquídea).

Usei a gravidez todinha. Todos os dias... Sabia que era errado, mas o vício era muito grande. Se não tivesse usado, já tava em casa com ela (Lírio).

Não sabia... Aliás, até sabia, mas sei lá... (Jasmim).

A partir dos relatos, verificou-se que as gestantes tiveram dificuldade para ficar em abstinência e que as principais drogas utilizadas foram maconha, cocaína e crack, sendo o tempo de uso superior a um ano em todos os casos.

No caso dessas gestantes usuárias de drogas, os profissionais têm maior dificuldade de identificá-las, pois as informações sobre o seu consumo e frequência muitas vezes não são percebidas a tempo de diminuir os efeitos sobre o feto ${ }^{(14)}$.

Eu já usei tudo! (Girrasol).

Eu uso crack... (Tulipa).

Só usei cocaína... (Jasmim).

Usava crack. Também fumava e bebia cerveja... (Lírio).

... queria parar de usar a cocaína e a maconha, mais não consegui (Margarida).

Conseguia parar 3 dias a uma semana sem usar... (Lírio).

Nenhum momento eu deixei de usar. Comecei usando pra esquecer e depois vi que tava praticamente viciada. Não conseguia passar uma noite sem usar (Jasmim).

De acordo com o apreendido, as gestantes não relacionavam o uso de drogas com a gestação, não deixando de utilizá-las. Percebe-se, com isso, a falta de conhecimento no tocante à sua própria saúde e à do bebê.

Situação saúde/doença das puérperas

Verificou-se a falta de conhecimento sobre a situação de saúde e doença e as suas formas de transmissão.

... essa doença que eu tô mata? (Tulipa). (Tulipa).

... o outro doutor disse que eu peguei essa doença no sexo

... eu já tô de alta (Hortência). 
Durante a realização das entrevistas, foi possível verificar que seis puérperas tinham sífilis, não sendo rastreado durante o pré-natal e, consequentemente, transmitiram para o feto na gestação.

A análise das falas das entrevistadas permite dizer, mais uma vez, que o conhecimento revelado por elas ainda é bastante restrito, principalmente no tocante à prevenção das doenças, à gestação e à relação com o uso de drogas.

As percepções delas não se modificaram na vigência da gestação, fato que pode ser ressaltado devido ao despreparo emocional e racional ante uma gravidez.

\section{Discussão}

O uso de drogas continua sendo um grande problema de saúde pública, repercutindo de maneira assustadora na sociedade em que vivemos. Nas gestantes, esse problema ganha mais importância, pois a exposição dessas pacientes às drogas pode levar ao comprometimento irreversível da integridade do binômio mãe/feto ${ }^{(5)}$.

De acordo com a Organização Mundial de Saúde (OMS), os programas de saúde da mulher devem enfatizar o rastreamento de gestantes nas áreas em que o consumo de drogas seja frequente, visando prevenir e detectar precocemente esse grupo de risco. Torna-se pertinente também a sensibilização dos gestores de saúde sobre a necessidade de educação continuada para os profissionais, bem como a realização de mais estudos que permitam identificar os principais grupos de risco, para que as intervenções sejam implementadas de forma eficaz.

Em um estudo sobre o consumo de drogas, durante a gestação, o mesmo está associado a fatores como: relações pessoais, características individuais, meio ambiente, ausência de parceiro fixo, menor escolaridade, uso de drogas pelo pai do concepto e histórico de violência antes e durante a gestação ${ }^{(15)}$.

A importância do pré-natal deve ser reforçada para essas gestantes, pois o acompanhamento adequado permite a identificação das situações de risco precocemente, prevenindo os resultados negativos na gestação, no período neonatal e a ocorrência de óbitos ${ }^{(16)}$.

A frequência e a regularidade no acompanhamento do pré-natal permitem o desenvolvimento do vínculo entre a gestante e o profissional de saúde, o que possibilita o aprofundamento da relação com maior troca de informações, facilitando a identificação de hábitos de vida prejudiciais à saúde, como o uso inadequado de álcool e drogas ${ }^{(17)}$.

É preciso, portanto, oferecer atenção integral à saúde da mulher durante a gestação, que contemple as suas necessidades psicossociais, examinando a situação em que ela está inserida, os comportamentos destrutivos, suas histórias de vida e se engajando na atenção às mulheres grávidas em situação de pobreza, relacionamentos violentos e comportamentos autodestrutivos como o uso de drogas.

Outro ponto fundamental na atenção à saúde da gestante é o enfoque da responsabilidade paterna. É preciso que os homens se sintam responsáveis pela saúde e pelo bem-estar fetal, proporcionando mudanças dos comportamentos que colocam seus descendentes em situações de risco $^{(18)}$.
A dependência química tende a afetar a família como um todo. Os filhos de usuárias de drogas possuem risco aumentado para o desenvolvimento de dependência química, futuramente, além de transtornos mentais e de problemas emocionais como baixa autoestima, fobia social, depressão, ansiedade e dificuldade de relacionamento ${ }^{(19)}$.

As complicações mais presentes no estudo foram: sífilis congênita, icterícia, baixo peso ao nascer, prematuridade, desconforto respiratório e infecção neonatal. Esses dados repercutem na concatenação da não adesão ao pré-natal, à falta de conhecimento das gestantes e ao desejo de parar de usar drogas.

A sífilis congênita foi a ocorrência mais prevalente neste estudo, afetando sete RNs e é causada pela disseminação hematogênica por via transplacentária do Treponema pallidum da gestante não tratada, ou inadequadamente tratada, para o seu concepto. A transmissão pode ocorrer em qualquer fase da gestação e em qualquer estágio da doença ${ }^{(20)}$.

A icterícia, presente em quatro RNs, é um dos problemas mais comuns no período neonatal. Corresponde ao aumento de bilirrubina no sangue e, geralmente, é benigna. Porém, devido à toxicidade potencial da bilirrubina, os RNs de risco devem ser monitorados para prevenir o desenvolvimento de hiperbilirrubinemia significativa e de encefalopatia bilirrubínica ${ }^{(21)}$.

O baixo peso ao nascer e a prematuridade são os principais fatores de risco para a mortalidade fetal e neonatal. $\mathrm{O}$ efeito do baixo peso repercute no crescimento e desenvolvimento infantil durante o primeiro ano de vida, sendo relevante também para a mortalidade infantil ${ }^{(16)}$.

O desconforto respiratório esteve presente em três RNs. O principal fator de risco para o desconforto respiratório é a prematuridade, sendo os outros fatores: cirurgia cesariana, sexo masculino, gestantes diabéticas, corioamnionite e gemelaridade ${ }^{(11)}$.

A infecção neonatal afetou três RNs do estudo, o que determina cuidados intensos pela equipe multiprofissional por ser uma patologia grave e de difícil diagnóstico, podendo ser congênita, adquirida durante o parto ou na vida pós-natal ${ }^{(22)}$.

Diante dessa realidade é necessário o emprego de assistência de qualidade a essa população, por meio do modelo holístico, onde cada cliente é tratado como um ser biopsicossocial e espiritual, havendo, então, acompanhamento direcionado para todas as suas necessidades ${ }^{(23)}$.

Para tanto, é necessária a preparação dos profissionais, em especial o enfermeiro, sobre o fenômeno das drogas na gestação e sua importância para melhor enfrentamento do problema, para que haja a promoção da saúde dessa clientela, a partir das medidas de prevenção do uso e abuso de drogas ilícitas.

\section{Considerações Finais}

A análise dos resultados encontrados neste estudo leva à identificação de uma população jovem e com baixa escolaridade. A maioria das gestantes era adolescente, fato que sinaliza a urgência do planejamento de ações eficazes 
para a promoção da saúde desse grupo de risco. Observouse a importância de considerar os hábitos de vida da gestante durante a anamnese, pois a coleta dessas informações possibilita o conhecimento do seu dia a dia, sendo mais fácil a escolha de estratégias mais eficazes durante a prestação dos cuidados na assistência, visando proporcionar maior qualidade de vida para o binômio mãe/filho.

Verificou-se, também, que o uso de drogas na gestação constitui-se um problema de saúde pública, pois foram identificados vários danos prejudiciais à saúde de todos os recém-nascidos, entres os quais se destacam: malformações congênitas, desconforto respiratório, infecção neonatal, baixo peso, icterícia, edema agudo de pulmão, sífilis congênita e sofrimento fetal. Vale ressaltar que quanto maior o período de exposição do feto às substâncias maiores foram as consequências deletérias.

Apesar de o uso de drogas ser assunto considerado um tema transversal, o qual deveria ser abordado durante todas as consultas nos serviços de saúde, a discussão e a troca de experiências entre os profissionais é pouco frequente, o que dificulta a identificação dos fatores de risco e das implicações ocasionadas na saúde da mulher e da criança, devido ao uso de drogas durante a gestação.

Acredita-se que os resultados encontrados disponibilizarão informações fundamentais para assistência às gestantes que utilizam drogas. Espera-se que os profissionais de saúde possam discutir essa temática e, consequentemente, identificar e intervir nessa situação. A partir deste estudo, propõe-se que maior número de pesquisas sejam desenvolvidas nessa temática para contribuir com conhecimento científico dos profissionais que atuam direta e indiretamente com essa população.

\section{Referências}

1. Murphy JG, Devitt-Murphy ME. Barnett - Drink and be merry? Gender, life satisfaction, and alcohol consumption among college students. Psychol Addictive Behav. 2005 Jun;19(2):184-91.

2. Stempliuk VA, Barroso LP, Andrade AG, Nicastri S, Malbergier A. Comparative study of drug use among undergraduate students at the University of São Paulo São Paulo campus in 1996 and 2001. Rev Bras Psiquiatria. 2005 Dec;27(3):185-93.

3. Boland M, Fitzpatrick P, Scallan E, Daly L, Herity B, Horgan J, et al. Trends in medical student use of tobacco, alcohol and drugs in an Irish university, 1973-2002. Drug Alcohol Depend. 2006 Apr;85:123-8.

4. Lucas ACS, Parente RCP, Picanço NS, Conceição DA, Costa KRC, Magalhães IRS, et al. Uso de psicotrópicos entre universitários da área da saúde da Universidade Federal do Amazonas, Brasil. Cad Saúde Pública. 2006 Mar;22(3):663-71.

5. Yamaguchi ET, Cardoso MMSC, Torres MLA, Andrade AG. Drogas de abuso e gravidez. Rev Psiquiatr Clín. 2008;35(1):44-7. 6. Office of Applied Studies. Pregnancy and illicit drug use. Rockville: Department of Health and Human Services; 2001. 7. Substance Abuse and Mental Health Services Administration. Results from the 2007 National Survey on
Drug Use and Health: national findings. (NSDUH Series H-34, DHHS Publication No. SMA 08-4343). Rockville: Department of Health and Human Services; 2008.

8. Pinheiro SN, Laprega MR, Furtado EF. Morbidade psiquiátrica e uso de álcool em gestantes usuárias do Sistema Único de Saúde. Rev Saúde Pública. mar 2005;39(4):593-8.

9. Polit DF, Beck CT, Hungler BP. Fundamentos de pesquisa em enfermagem. $5^{\mathrm{a}}$ ed. São Paulo (SP): Artmed; 2004. 38 p. 10. Bardin L. Analise de conteúdo. Lisboa: Edições Setenta; 2004. 67 p.

11. Ministério da Saúde (BR). Conselho Nacional de Saúde. Diretrizes e Normas Regulamentadoras de Pesquisa Envolvendo Seres Humanos. Resolução 196, de 1996. Brasília; 1996.

12. Camacho RS, Cantinelli FS, Ribeiro CS, Cantilino A, Gonsales BK, Braguittoni E, et al. Transtornos psiquiátricos na gestação e no puerpério: classificação, diagnóstico e tratamento. Rev Psiquiatr Clín. mai 2006;33(2):92-102.

13. Silva EA, Camargo BMV, Pavin T, Noto AR, Buscatti $\mathrm{D}$, Sartori V, et al. As drogas no âmbito familiar, sob a perspectiva do cinema. Psicol Teoria Prática. jun 2008;10(1):214-22.

14. Casatti, GFS. Projeto de intervenção social com gestante e/ou puérperas, usuárias de drogas ilícitas e/ou lícitas. Ensaios Ciênc. ago 2011;15(1):97-120.

15. Oliveira EFB, Gama SGN, Silva CMFP. Gravidez na adolescência e outros fatores de risco para mortalidade fetal e infantil no Município do Rio de Janeiro, Brasil. Cad Saúde Pública. mar 2010;26(3):567-78.

16. Moraes CL, Reichenheim ME. Rastreamento de uso de álcool por gestantes de serviços públicos de saúde do Rio de Janeiro. Rev Saúde Pública. mai 2007;41(5):695-703.

17. Rodrigues DT, Nakano AMS. Violência doméstica e abuso de drogas na gestação. Rev Bras Enferm jan-fev. 2007;60(1):77-80.

18. Figlie N, Fontes A, Moraes E, Paya R. Filhos de dependentes químicos com fatores de risco biopsicossociais: necessitam de um olhar especial? Rev Psiquiatr Clín. fev 2004;31(2):53-62.

19. Secretaria do Estado da Saúde de São Paulo (BR). Centro de Referência e Treinamento em DST/AIDS-São Paulo, Programa Estadual de DST/AIDS. Eliminação da transmissão vertical do HIV e da sífilis no Estado de São Paulo. Rev Saúde Pública. dez 2011;45(4):812-5.

20. Newman TB, Liljestrand P, Escobar GJ. Combining clinical risk factors with serum bilirubin levels to predict hyperbilirubinemia in newborns. Arch Pediatr Adolesc Med 2005 Feb;(159):113-9.

21. Silva TP, Tocci HA. Efeitos obstétricos, fetais e neonatais relacionados ao uso de drogas, álcool e tabaco durante a gestação. Rev Enferm UNISA. jan 2002;(3):50-6.

22. Costa TS, Vasconcelos TC, Sousa LB, Bezerra CP, Miranda FAN, Alves SGS. Percepções de adolescentes grávidas acerca do consumo de álcool durante o período gestacional. SMAD, Rev Eletr Saúde Mental Álcool Drogas.(ed. Port). [Internet]; abr-jul 2010; [acesso 13 jan 2011]. 6(1):1-15. Disponível em: http://pepsic.bvsalud. org/pdf/smad/v6n1/03.pdf 